\title{
MACROMEDIA FLASH UNTUK INOVASI PENGAJARAN MATEMATIKA DAN SAINS SDN KOTA BAUBAU
}

\author{
Moh. Ali \\ Fakultas Keguruan dan Ilmu Pendidikan Universitas Muhammadiyah Buton J1. \\ Betoambari No. 36 Kota Baubau, 93721, Indonesia. \\ Email: a.muh.ali@umbuton.ac.id
}

\begin{abstract}
Abstrak
Program smart city yang akan diterapkan pemerintah Kota Baubau di tahun 2019 salah satunya adalah meningkatkan kualitas SDM di sekolah. Sekolah SDN 4 Katobengke dan SDN 4 Wameo merupakan sekolah favorit yang berada di pusat kota Baubau. Di sekolah tersebut sudah menerapkan pembelajaran kurikulum 2013 (K13), namun guru-guru mata pelajaran khususnya mata pelajaran matematika dan sains masih mengajarkan konsep dengan gambar dan angka yang tidak bergerak. Macromedia Flash adalah lingkungan berbasis animasi vektor yang menciptakan pengalaman multimedia interaktif, mampu menampilkan animasi gambar bergerak dan video tiga dimensi yang sangat tepat untuk bahan ajar matematika (geometri) dan pengajaran sains (mahluk hidup) sehingga siswa lebih senang dalam proses belajar. Aplikasi ini berbasis sistem operasi sehingga membutuhkan pelatihan/kursus bagi guru agar bisa mengoperasikan aplikasinya, Melalui PKM ini pengabdi bekerja sama dengan sekolah untuk memberikan kursus pelatihan Macromedia Flash bagi guru-guru, mensosialisasikan melalui unit KKG dan menjadi multifer effect yakni kesadaran akan pentingnya pemanfaatan teknologi media pembelajaran bagi guru-guru dilingkungannya dan masyarakat pada umumnya.
\end{abstract}

Kata Kunci: Macromedia Flash, Pelajaran Matematika dan Sains SD

\section{A. Pendahuluan}

Kota Baubau memiliki luas wilayah lebih kurang 221,00 km². Achmad Fahrudin (2017), Wilayah administratif Kota Baubau meliputi delapan kecamatan yang terbagi atas enam kecamatan pesisir dan dua kecamatan bukan pesisir. Secara geografis terletak di bagian selatan garis khatulistiwa di antara $5.21^{\circ}-$ $5.33^{\circ}$ Lintang Selatan dan di antara $122.30^{\circ}-122.47^{\circ}$ Bujur Timur atau terletak di sebelah Selatan Provinsi Sulawesi Tenggara. Kota Baubau sebagai kota maritim dengan pelabuhan yang merupakan gerbang Indonesia bagian timur punya potensi 
yang cukup besar untuk menjadi kota besar. Di tahun 2018 Pemerintah kota Baubau melalui Dinas Pendidikan Komunikasi dan Informatika juga melakukan program kerjasama (MoU) dengan Pemkot Makassar untuk merancang program smartcity yang difasilitasi Sekretariat APEKSI Komwil VI Indonesia Timur di Makassar (www.baubaukota.go.id/diskominfo) . Dengan program kota smartcity yang didukung budaya modernisasi, masyarakat di Baubau secara tidak langsung akan tertinggal jika mereka tidak mengikuti perkembangan globalisasi dan modernisasi. Masyarakat khususnya di kota Baubau yang tidak memiliki kecakapan dalam teknologi informasi akan tergeser oleh peradaban, sehingga sekolah dan perguruan tinggi dituntut memberikan bekal kepada siswa siswinya untuk menguasai teknologi informasi. Di beberapa sekolah khususnya yang dijadikan pengabdi sebagai lokasi pengabdian menemukan bahwa guru-guru belum memaksimalkan teknologi komunikasi dalam proses pembelajaran. Masykur R (2017), “Seiring Pesatnya perkembangan ilmu pengetahuan, teknologi dan arus globalisasi yang makin cepat diera saat ini, banyak sekali aplikasiaplikasi komputer yang diluncurkan seperti Geogebra, Microsoft Powerpoint, Mathemathica 7, Adobe Flash, Macromedia Flash, dll yang seharusnya sudah bisa dimanfaatkan oleh para pendidik di Indonesia untuk mengembangkan sebagai bahan ajar khususnya dalam pembelajaran matematika dan sains, metode konvensional dirasa sudah tidak relevan lagi digunakan”.

Pengabdi memilih 2 sekolah mitra yakni Sekolah SDN. 4 Katobengke dan SDN. 4 Wameo karena sekolah ini terletak di pusat kota Baubau dengan padat penduduk, dan menjadi sekolah favorit bagi orang tua untuk mencerdaskan anaknya di sekolah tersebut.

Sekolah SDN 4 Katobengke terletak di jalan Sibatara RT/RW 3/4 Kelurahan Lipu Kecamatan Betoambari Kota Baubau, sejak diresmikan pada tanggal 31 Desember 1983 sekolah ini sudah status akreditasi B, jumlah guru yang mengajar 33 guru, ruang kelas berjumlah 24 dan jumlah siswa kurang lebih 653 siswa, dan dalam proses pembelajaran sudah menerapkan kurikulum K.13 khususnya untuk kelas tinggi. Sekolah SDN. 4 Wameo terletak di Kel. Wameo, Kec. Batupuaro, Kota Baubau. Guru di sekolah ini berjumlah 13 orang, kurikulum 
yang diterapkan adalah kurikulum KTSP, dan sementara menunggu akreditasi B. Kedua sekolah ini dan sekolah SDN yang ada di Kota Baubau umumnya sangat membutuhkan pendampingan pembelajaran inovasi pembelajaran berbasis telknologi komunikasi. Harapannya melalui pengabdian ini, tantangan yang dihadapi oleh kedua mitra bisa terbantu, dengan tahapan pelatihan, pengoprasioan dan sosialisasi ke pada kelompok kerja guru yang ada di Kota Baubau.
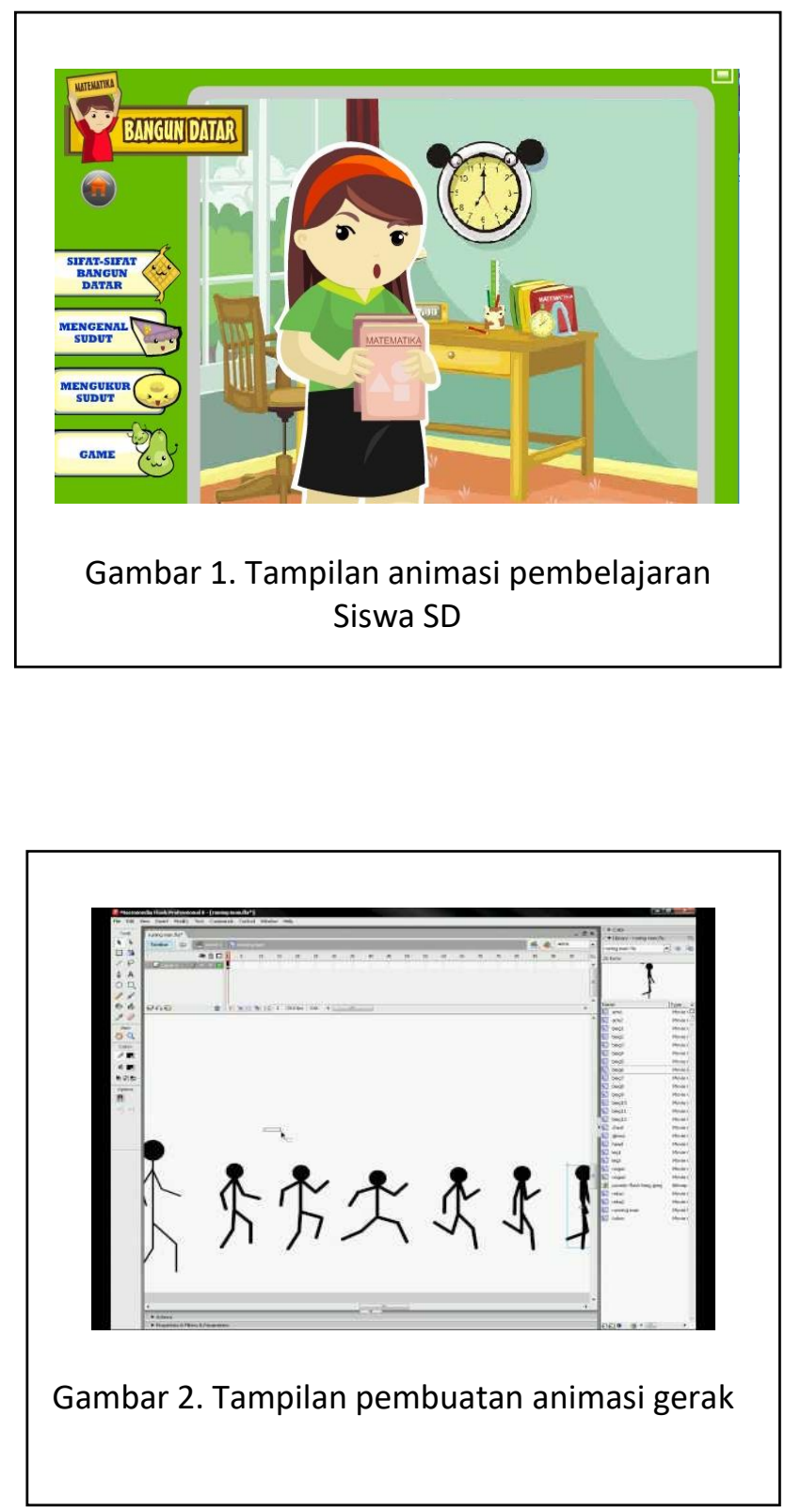


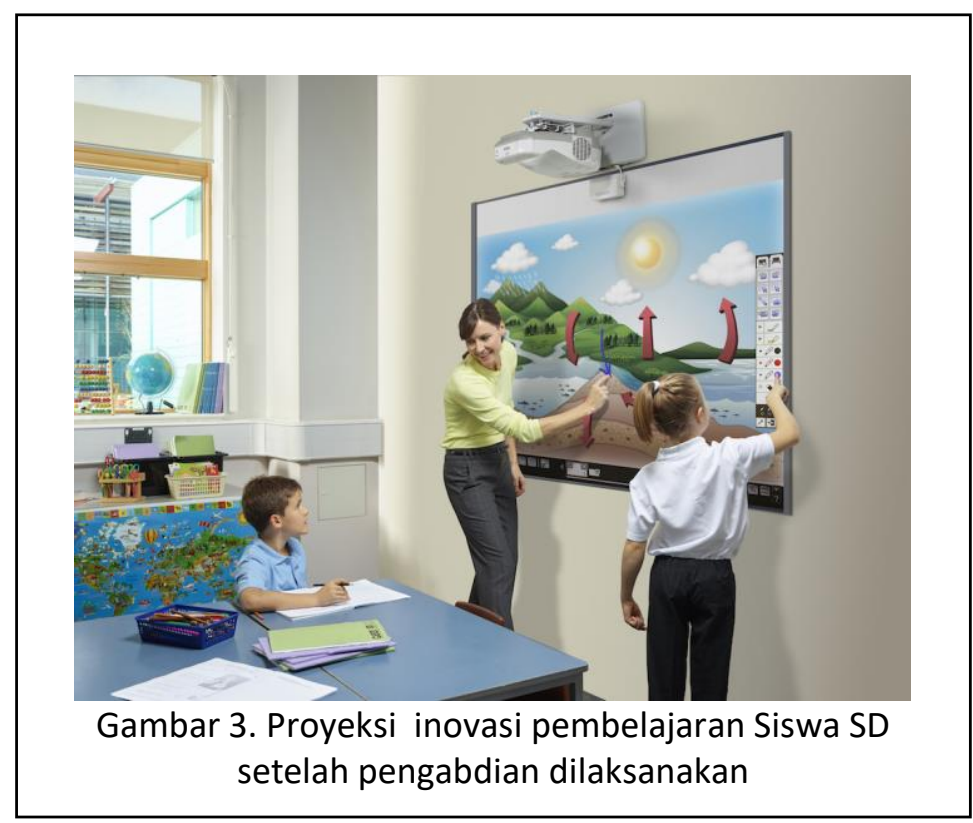

\section{B. Masalah}

Berdasarkan hal tersebut, maka masalah program Kemitraan Masyarakat (PKM) yang dilaksanakan di sekolah SDN 4 Katobengke dan SDN 4 Wameo yaitu:

Para guru belum mengetahui akan peran dan pentingnya pembelajaran berbasis multimedia, pemanfaatan pembelajaran multimedia, mengoperasikan software Macromedia Flash, pembuatan media gambar gerak dalam materi matematika menggunakan software Macromedia Flash dan membuat desain dan perangkat pembelajaran di kelas menggunakan pembelajaran macromedia.

\section{Metode Pelaksanaan}

\section{Uraian Penentuan Permasalahan Prioritas Mitra}

Berdasarkan permasalahan mitra PKM, maka berdasarkan kebutuhan dan kesepakatan dengan mitra maka telah dirumuskan prioritas permasalahan dan solusi yang akan ditawarkan, sebagai berikut: Permasalahan keterampilan dan sarana penunjang pembelajaran yang kurang lengkap yang dihadapi oleh mitra, oleh sebab itu para guru akan dilatih tentang pemahaman dan keterampilan membuat animasi pembelajaran berbasis multimedia dengan memanfaatkan software Macromedia Flash . 
Permasalahan peningkatan kualitas guru menjadi pengajar professional akan dilakukan dengan mengadakan kursus selama 72 jam selama kurang lebih 3 bulan dengan tahapan pengenalan software Macromedia Flash, pelatihan tutorial membuat animasi gerak, dan membuat animasi pembelajaran matematika. Safitri Meilani (2013), selanjutnya dilakukan analisis materi yang akan dikembangkan dengan menggunakan macromedia flash, tahap ini bertujuan untuk mengidentifikasi dan memilih materi esensial yang akan ditampilkan pada media ajar menggunakan macromedia flash. Kemudian tahap ini dilanjutkan dengan membuat flowchart yang bertujuan untuk menentukan urutan materi pembelajaran yang akan ditampilkan pada medi aajar, serta menentukan materi apa saja yang dapat dibuat bangun geometrinya baik berupa animasi maupun simulasi. setelah guru mengetahui langkah-langkah pengoperasiannya diharapkan untuk mensosialisasikan pengajaran ini melaui KKG sehingga kualitas pendidikan dapat meningkat.

\section{Pembahasan}

Peletakan dasar ilmu matematika sangat penting. Afidah (2015) "Matematika di gunakan di seluruh dunia sebagai alat penting di berbagai bidang, termasuk ilmu alam dan ilmu sosial". Proses pembelajaran khususnya mata pelajaran matematika dan sains di sekolah tersebut masih mengajarkan materi dengan cara yang biasa (tulisan dan gambar yang tidak bergerak) padahal siswa sudah menonton youtube (video gambar bergerak) diluar sekolah sebagai sarana belajar mereka, sehingga siswa tidak mendapat pengalaman baru dalam proses pembelajaran. Untuk merencanakan pembelajaran yang baik perlu pemanfaatan media. Menurut, Ali Hamzah (2014) "Pemanfaatan berbagai media dan sumber belajar dalam kegiatan belajar mengajar akan membuka peluang yang lebih besar bagi terciptanya kondisi belajar mengajar yang efektif”. Sejalan dengan itu, Kusuma dalam (Mekar Arum. 2015) "media pembelajaran adalah segala sesuatu yang dapat digunakan untuk menyalurkan informasi dari guru ke siswa dalam mata pelajaran, hingga dapat mengrangsang pikiran, perasaan, perhatian dan minat siswa dan pada akhirnya padat menjadikan siswa melalukukan kegiatan belajar mengajar". Dapat disimpulkan bahwa pembelajaran untuk era digital 
memerlukan inovasi yang bernuansa digital pula sehingga siswa mampu memahami konsep pelajaran dan juga mereka bisa mengikuti perkembangan zaman. Dalam hal ini pengabdi memilih macromedia flash sebagai salah satu software untuk memberikan inovasi materi ajar khususnya di sekolah dasar. Mawarni (2015) "Macromedia flash adalah lingkungan berbasis animasi vektor yang memungkinkan penciptaan yang sangat dinamis dan pengalaman multimedia interaktif'.

Data dinas pendidikan dan kebudayaan Kota Baubau menerangkan anggaran untuk peningkatan SDM guru cukup besar yang direalisasikan melalui pelatihan, seminar, workshop, Pengabdian PTK dan pendidikan (Kendari pos.co.id , 2017). Sesuai dengan fakta dilapangan, guru yang mengikuti pelatihan tersebut hanya mengejar sertifikat dan angka kredit sehingga pengalaman yang diperoleh belum maksimal ditambah lagi pelatihan-pelatihan yang guru-guru ikuti hanya mengggunakan diktat dan tampa melibatkan teknologi komunikasi sehingga tidak ada pengalaman praktis untuk bisa mengajar dikelas dengan profesional. Dari pantauan survey lapangan, media yang biasa digunakan oleh guru dalam mengajar adalah buku paket, alat peraga sederhana yang terbuat dari kertas tebal, dan ada beberapa alat peraga yang disediakan oleh pemerintah yang terbuat dari besi dan plastik, padahal pembelajaran matematika dan sains memerlukan pendekatan yang menarik sehingga siswa senang belajar.

Secara keseluruhan, kegiatan PKM Macromedia Flash untuk guru mata pelajaran matematika dan Sains ini akan dilaksanakan dengan metode pendekatan sebagai berikut:

a. Sosialisasi kepada pihak sekolah untuk melaksanakan pelatihan dan kursus pembelajaran

b. Pengenalan dan sosialisasi pembelajaran berbasis multimedia kepada guru-guru.

c. Pengenalan dan pelatihan cara menggunakan software Macromedia Flash kepada guru-guru.

d. Pelatihan cara membuat animasi pembelajaran yang menarik kepada guru-guru khususnya membuat media ajar matematika dan Sains. 
e. Pendampingan kepada guru-guru untuk menerapkan pembelajaran berbasis multimedia dikelas pada mata pelajaran matematika.

Memalui pelatihan tersebut diharapkan dapat membantu para guru dalam membuat media pembelajaran berbasis teknologi yang inovatif dan membantu siswa menyukai proses pembelajaran mata pelajaran matematika. dan diharapkan guru-guru mensosialisasikan melalui unit KKG dan menjadi multifer effect yakni kesadaran akan pentingnya pemanfaatan teknologi media pembelajaran bagi guru-guru dilingkungannya.

Kegiatan Pengabdian ini dilakukan selama delapan bulan yang terdiri dari tiga tahapan: (1) Tahap Perencanaan, (2) Tahap Pelaksanaan, dan (3) Tahap Evaluasi.

1. Tahap Perencanaan telah ditetapkan hal-hal sebagai berikut:

a. Melakukan pendekatan kepada pemangku kepentingan setempat untuk memulai menawarkan solusi dari permasalahan yang ada. Pendekatan dilakukan kepada kepalasekolah SDN. 4 Katobengke dan SDN. 4 Wameo

b. Bersama dengan pemangku kepentingan membuat persetujuan program dan kesepakatan untuk dukungan kegiatan.

c. Menyiapkan materi-materi dan prosedur yang akan digunakan pada penerapan Macromedia Flash.

d. Memberikan penjelasan tentang mekanisme kursus dan pelatihan baik berupa jadwal maupun tata tertibnya.

e. Menyusun jadwal kegiatan pelatihan yang akan diberikan kepada kepala sekolah SDN. 4 Katobengke dan SDN. 4 Wameo.

2. Tahap Pelaksanaan Kegiatan.

a. Menyediakan LCD proyektor, laptop dan Software aplikasi Macromedia Flash kepada pihak sekolah.

b. Memberikan penyuluhan/penyampaian materi tentang media pembelajaran berbasis multimedia kepada pihak Sekolah SDN. 4 Katobengke dan SDN. 4 Wameo 
c. Melakukan kursus dan pelatihan penggunaan aplikasi Macromedia Flash kepada guru-guru khususnya guru matematika dan sains.

3. Tahap Evaluasi terdiri atas:

a. Melakukan evaluasi terhadap kemampuan dan pemahaman guru (kgnitif) mengoperasikan software Macromedia Flash.

b. Melakukan evaluasi terhadap kemampuan praktik/psikomotor terhadap pembelajaran Macromedia Flash.

c. Melakukan evaluasi tindak lanjut pendampingan kepada guru baik dalam pengoperasiannya maupun pelatihan membuat media pembelajarannya.

\section{E. Kesimpulan}

SDN. 4 Katobengke dan SDN. 4 Wameo merupakan sekolah favorit yang berada di pusat kota Baubau. Di sekolah tersebut sudah menerapkan pembelajaran kurikulum 2013 (K13), namun guru-guru mata pelajaran khususnya mata pelajaran matematika dan sains masih mengajarkan konsep dengan gambar dan angka yang tidak bergerak. Macromedia Flash adalah lingkungan berbasis animasi vektor yang menciptakan pengalaman multimedia interaktif, mampu menampilkan animasi gambar bergerak dan video tiga dimensi yang sangat tepat untuk bahan ajar matematika (geometri) dan pengajaran sains (mahluk hidup) sehingga siswa lebih senang dalam proses belajar. Aplikasi ini berbasis sistem operasi sehingga membutuhkan pelatihan/kursus bagi guru agar bisa mengoperasikan aplikasinya, Melalui PKM ini pengabdi bekerja sama dengan sekolah untuk memberikan kursus pelatihan Macromedia Flash bagi guru-guru, mensosialisasikan melalui unit KKG dan menjadi multifer effect yakni kesadaran akan pentingnya pemanfaatan teknologi media pembelajaran bagi guru-guru dilingkungannya dan masyarakat pada umumnya. 


\section{DAFTAR PUSTAKA}

Achmad Fahrudin. Analisis Keberlanjutan Pembangunan Kota Tepian Pantai (Studi Kasus: Kota Baubau Provinsi Sulawesi Tenggara. Jurnal Wilayah dan Lingkungan. E-ISSN: 2407-8751. 2017

Ali Hamzah, Muhlisrarini, Perencanaan Dan Strategi Pembelajaran Matematika. Jakarta : Rajawali Pers. 2014

Afidah, Khaerunnisa. Matematika Dasar. Jakarta: Rajawali Press. 2015

Diskominfo. Baubau dan Makassar Gagas MoU Smart City. Blogspot Pemkot Baubau http://www.baubaukota.go.id/detailpost/diskominfo-baubau-dan-makassar-gagasmou-smart-city (diakses 17 Agustus 208)

Masykur R. Pengembangan Media Pembelajaran Matematika dengan Macromedia Flash . Jurnal Aljabar. ISSN: 2086-5872. 2017

Mawarni Enggar, Bakti Mulyani, Sri Yamtinah, Penerapan Peer Tutoring Dilengkapi Animasi Macromedia Flash Dan Handout Untuk Meningkatkan Motivasi Berprestasi Dan Prestasi Belajar Siswa Kelasxi Ipa 4 Sman 6 Surakarta. Jurnal Pendidikan Kimia. ISSN: 2337-9995. 2015

Mekar Arum, Media Pembelajaran E.Macromedia Flash. Blogstpot http://mekar-arumkusuma.blogspot.com/2015/04/media-pembelajaran-emacromedia-flash.html. (diakses 17 Agustus 2018)

Safitri Meilani, Pengembangan Media Pembelajaran Matematika Pokok bahasan Segitiga Menggunakan Macromedia Flash Untuk Siswa Kelas 7 SMP. Jurnal Pendidikan. E-ISSN: 2443-3586. 2013 